\title{
Princeton Plasma Physics Laboratory
}

PPPL-4036

PPPL-4036

\section{Internal Kink Mode Dynamics in High- $\beta$ NSTX Plasmas}

J.E. Menard, R.E. Bell, E.D. Fredrickson, D.A. Gates, S.M. Kaye, B.P. LeBlanc, S.S. Medley, W. Park, S.A. Sabbagh, A. Sontag, D. Stutman, K. Tritz, W. Zhu, and the NSTX Research Team

December 2004
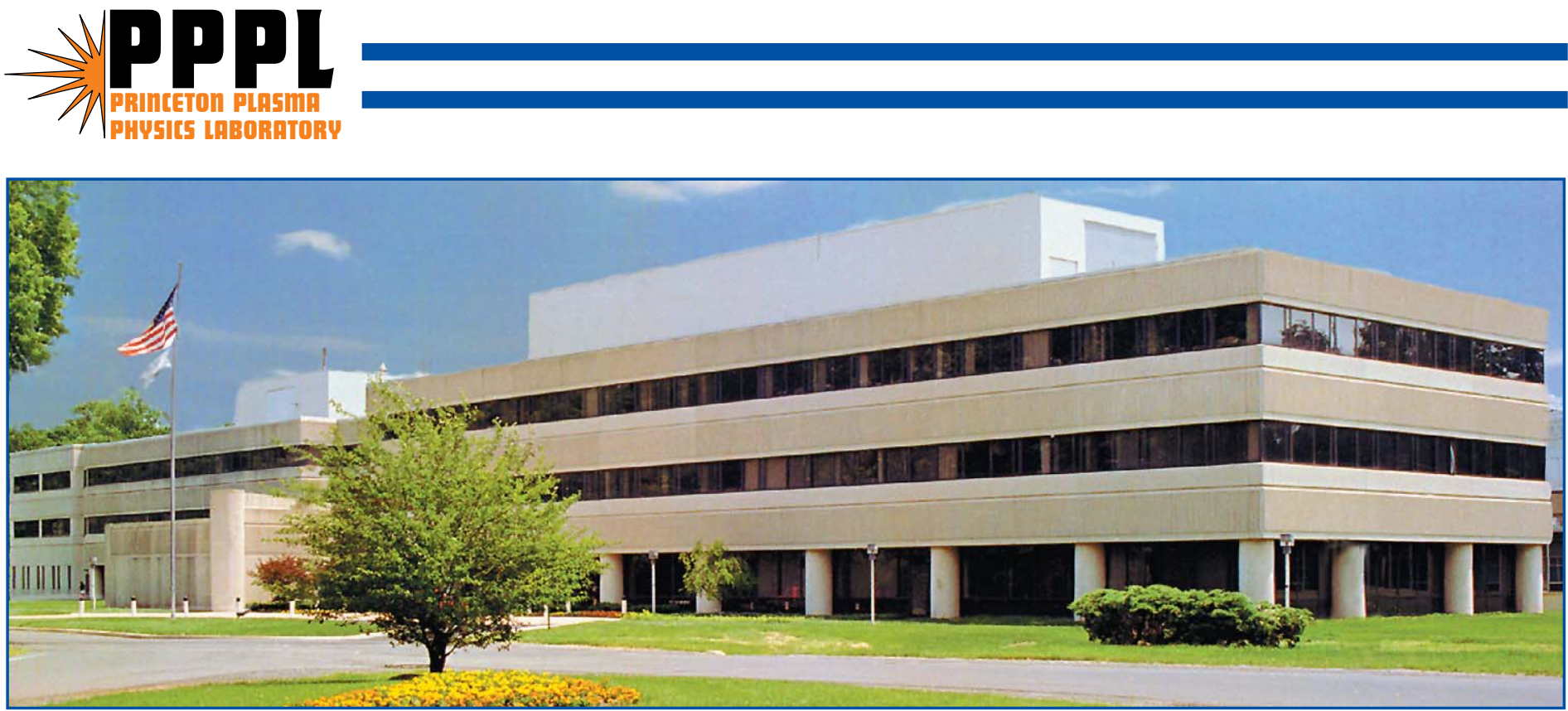

Prepared for the U.S. Department of Energy under Contract DE-AC02-76CH03073. 


\section{PPPL Report Disclaimers}

\section{Full Legal Disclaimer}

This report was prepared as an account of work sponsored by an agency of the United States Government. Neither the United States Government nor any agency thereof, nor any of their employees, nor any of their contractors, subcontractors or their employees, makes any warranty, express or implied, or assumes any legal liability or responsibility for the accuracy, completeness, or any third party's use or the results of such use of any information, apparatus, product, or process disclosed, or represents that its use would not infringe privately owned rights. Reference herein to any specific commercial product, process, or service by trade name, trademark, manufacturer, or otherwise, does not necessarily constitute or imply its endorsement, recommendation, or favoring by the United States Government or any agency thereof or its contractors or subcontractors. The views and opinions of authors expressed herein do not necessarily state or reflect those of the United States Government or any agency thereof.

\section{Trademark Disclaimer}

Reference herein to any specific commercial product, process, or service by trade name, trademark, manufacturer, or otherwise, does not necessarily constitute or imply its endorsement, recommendation, or favoring by the United States Government or any agency thereof or its contractors or subcontractors.

\section{PPPL Report Availability}

This report is posted on the U.S. Department of Energy's Princeton Plasma Physics Laboratory Publications and Reports web site in Fiscal Year 2005. The home page for PPPL Reports and Publications is: http://www.pppl.gov/pub_report/

\section{Office of Scientific and Technical Information (OSTI):}

Available electronically at: http://www.osti.gov/bridge.

Available for a processing fee to U.S. Department of Energy and its contractors, in paper from:

U.S. Department of Energy

Office of Scientific and Technical Information

P.O. Box 62

Oak Ridge, TN 37831-0062

Telephone: (865) 576-8401

Fax: (865) 576-5728

E-mail: reports@adonis.osti.gov

\section{National Technical Information Service (NTIS):}

This report is available for sale to the general public from:

U.S. Department of Commerce

National Technical Information Service

5285 Port Royal Road

Springfield, VA 22161

Telephone: (800) 553-6847

Fax: (703) 605-6900

Email: orders@ntis.fedworld.gov

Online ordering: http://www.ntis.gov/ordering.htm 


\title{
Internal kink mode dynamics in high- $\beta$ NSTX plasmas
}

\author{
J.E. Menard 1), R.E. Bell 1), E.D. Fredrickson 1), D.A. Gates 1), S.M. Kaye 1), \\ B.P. LeBlanc 1), S.S. Medley 1), W. Park 1) S.A. Sabbagh 2), A. Sontag 2), \\ D. Stutman 3), K. Tritz 3), W. Zhu 2), and the NSTX Research Team. \\ 1) Princeton Plasma Physics Laboratory, Princeton, NJ, USA \\ 2) Columbia University, New York, NY, USA \\ 3) Johns Hopkins University, Baltimore, MD, USA \\ email-contact of main author: jmenard@pppl.gov
}

\begin{abstract}
Saturated internal kink modes have been observed in many of the highest toroidal beta discharges of the National Spherical Torus Experiment (NSTX). These modes often cause rotation flattening in the plasma core, can degrade energy confinement, and in some cases contribute to the complete loss of plasma angular momentum and stored energy. Characteristics of the modes are measured using soft X-ray, kinetic profile, and magnetic diagnostics. Toroidal flows approaching Alfvénic speeds, island pressure peaking, and enhanced viscous and diamagnetic effects associated with high-beta may contribute to mode non-linear stabilization. These saturation mechanisms are investigated for NSTX parameters and compared to experiment.
\end{abstract}

\section{Introduction}

NSTX [1] has achieved both high toroidal- $\beta, \beta_{T} \equiv 2 \mu_{0}\langle p\rangle / B_{T 0}^{2}$ up to $35 \%$, and high normalized- $\beta, \beta_{N} \equiv \beta_{T} a B_{T 0} / I_{P}$ up to $6.5 \% \mathrm{mT} / \mathrm{MA}[2,3]$ using up to $7 \mathrm{MW}$ of deuterium Neutral Beam Injection (NBI) heating. In the highest $\beta_{T}$ discharges, obtained at high $I_{P} / a B_{T}>6 \mathrm{MA} / \mathrm{mT}$, the central safety factor inferred from EFIT reconstructions $[4,5,6]$ based on external magnetic measurements, simulations of resistive current diffusion, and preliminary Motional Stark Effect (MSE) data [7] is typically near 1 with a wide region of low magnetic shear. Such discharges are computed to be ideally unstable to $n=1$ pressuredriven internal kink instabilities, and experimentally the onset of $n=1$ activity is often observed near the computed instability thresholds. While operating regimes with high- $l_{i}$ and low to moderate beta exist in NSTX where periodic sawteeth are routinely observed, at high $\beta$, such sawteeth are relatively rare, and it is more common for a core $1 / 1$ mode to grow slowly and saturate in amplitude even for $\beta$ values well above the computed ideal (no-wall) limit at mode onset. In this paper we discuss the impact of the $1 / 1$ mode on fast-ion and thermal confinement and rotation. Methods for estimating the island mode structure from Ultra-Soft X-ray (USXR) [8] diagnostics are described, and the inferred mode fields are used to estimate rotation damping from neoclassical toroidal viscous (NTV) damping theory. Several possible saturation mechanisms for the $1 / 1$ mode are explored and compared to experimental data including: fast ion stabilization, strongly sheared toroidal flow, enhanced viscosity, pressure peaking inside the island, and nonlinearly enhanced diamagnetic flows.

\section{Experimental Results and Interpretation}

During the 2004 NSTX run campaign, techniques were adopted from DIII-D [9] to trigger an H-mode transition during the plasma current ramp. The early H-mode transition broadens the plasma pressure and bootstrap current profiles and increases the early plasma 
temperature. These effects, combined with lower- $l_{i}$ and higher elongation operation, have allowed significantly longer duration discharges by delaying the onset of deleterious MHD activity associated with the core safety factor being near 1 .
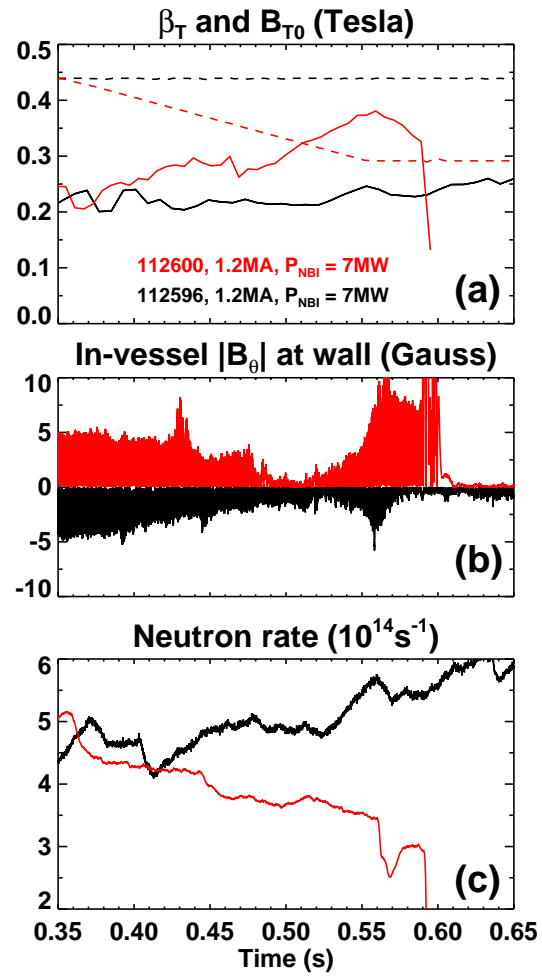

Figure 1: (a) $\beta_{T}$ (solid) and vacuum $B_{T}$ (dashed), (b) $B_{\theta}$ fluctuation amplitude, and (c) DD neutron rate.

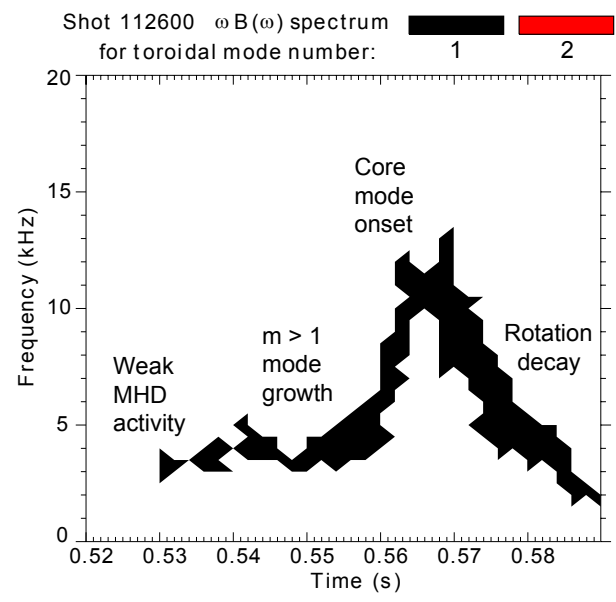

Figure 2: Frequency evolution of modes in high- $\beta$ shot 112600 .

This longer pulse-length allows the fast-ion heating and plasma stored energy to achieve more nearly steady-state values at elevated $q$. By using such discharges as high $\beta$ targets either by operating at fixed lower toroidal field ( $\mathrm{TF}$ ) or by ramping down the TF, plasmas with $\beta \geq 30 \%$ are now much more frequently obtained. Nevertheless, the onset and saturation of the $1 / 1$ mode can still limit the $\beta$ in these discharges by reducing the confinement and rotation either directly or through coupling to other modes. An example of this is shown in Figure 1 which compares a longpulse 1.2MA discharge at fixed vacuum toroidal field $B_{T}=0.44 \mathrm{~T}$ to a high- $\beta$ plasma obtained by ramping $B_{T}$ down from $0.44 \mathrm{~T}$ to $0.29 \mathrm{~T}$ with otherwise similar discharge conditions. Both discharges have a long-lived $n=1, m \geq 2$ mode present from early in the discharge which appears to be driven unstable by the early H-mode transition. The mode rotation frequency slows from $16 \mathrm{kHz}$ to $5 \mathrm{kHz}$ between $\mathrm{t}=240 \mathrm{~ms}$ and $520 \mathrm{~ms}$ and has a slowly decreasing magnetic fluctuation amplitude throughout this phase dropping to 1 Gauss amplitude by 520ms. The amplitude of the $n=1$ mode (possibly with different $m$ number) begins increasing again near $520-540 \mathrm{~ms}$ and remains rotating at $4-5 \mathrm{kHz}$ until $\mathrm{t}=560 \mathrm{~ms}$.

For the lower $\mathrm{TF}$ shot 112600 , near $\mathrm{t}=560 \mathrm{~ms}$, the $m / n=1 / 1$ mode becomes unstable, as evident in the neutron rate drop in Figure 1c and in the appearance of a $13 \mathrm{kHz} n=1$ mode, as shown in Figure 2. The frequency spectrogram of Figure 2 also suggests an early coupling between mid-radius and core modes, as the mid-radius mode frequency appears to increase in the early phase of the core mode growth. Later, during the saturation phase of the $1 / 1$ mode, one cannot distinguish between the two modes, as the modes appear to become phase-locked and rotate as a coupled structure.

This coupling is also evident in the USXR data shown in Figure 3a which indicates the presence of the $1 / 1$ mode (chords $6-14$ ) in addition to a midradius mode (chord 3 ) and edge perturbation (chord 1 ). The emission perturbation from the $1 / 1$ mode is large enough in fluctuation amplitude and spatial extent that important details of the mode structure can be inferred from the USXR data. Given the spatial resolution of the present arrays on NSTX, it is beneficial to constrain the SXR emission 
model of the plasma to more accurately infer the gross characteristics of the mode such as $q=1$ radius, island width, poloidal extent, propagation frequency, and magnetic field.

The model employed here assumes that only a single island helicity is present and that the local emission is a function of the total helical flux (equilibrium plus island). Emission line-integrals are computed numerically through normalized helical flux basis functions with varied island phase, and the emission profile is estimated using the measured line integrals and SVD inversion techniques. The best fit to the 1/1 island model is shown in Figure $3 \mathrm{~b}$. For this fit, the radial profile of the helical flux perturbation has been extended beyond the $\mathrm{q}=1$ radius (at $\mathrm{R}=1.2 \mathrm{~m}$ at the midplane) to reflect the non-zero displacement outside this radius.

Figure 4 shows that prior to the onset of the $1 / 1$ mode, the core rotation profiles for the discharges in Figure 1 are nearly identical despite the significantly lower TF of the higher $\beta$ discharge 112600 . Higher spatial and time resolution charge exchange data became available during the 2004 experiments, and Figure 4a shows significant rotation damping in the $10 \mathrm{~ms}$ between $\mathrm{t}=560 \mathrm{~ms}$ and $570 \mathrm{~ms}$ inside the inferred $q=1$ radius at $\mathrm{R}=1.2 \mathrm{~m}$. Interestingly, the rotation is observed to increase outside $R=1.3$ closer to the plasma edge, while dropping in the intermediate region. Since the core mode is observed to saturate without complete reconnection, other rotation damping mechanisms are likely at play in the core rotation decay of shot 112600 . Electromagnetic torque near the island singular surfaces [10] and enhanced neoclassical toroidal viscosity (NTV) [11, 12 ] arising from the loss of axisymmetry in the presence of the modes are likely candidates for explaining the rotational damping.

Using only the outer 4 channels of the data shown in Figure 3a, the best-fit helicity of the mid-radius perturbation is found to be $m / n=2 / 1$ with an island full-width of $12 \mathrm{~cm}$ at the outboard midplane. The perturbed radial field of both the $1 / 1$ and $2 / 1$ modes can be computed from the helical flux perturbation used to match the SXR emission fluctua-
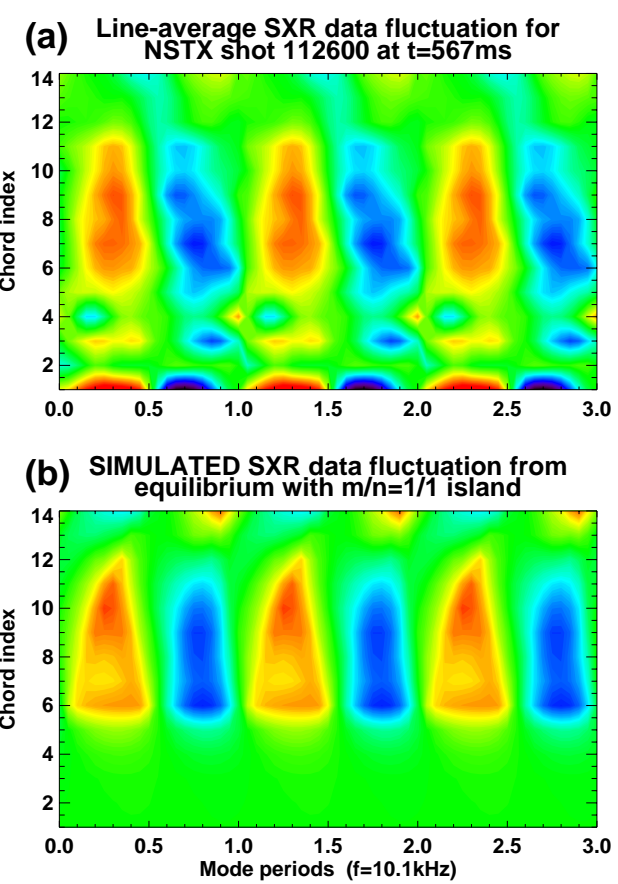

Figure 3: Contours of (a) measured and (b) model USXR data.
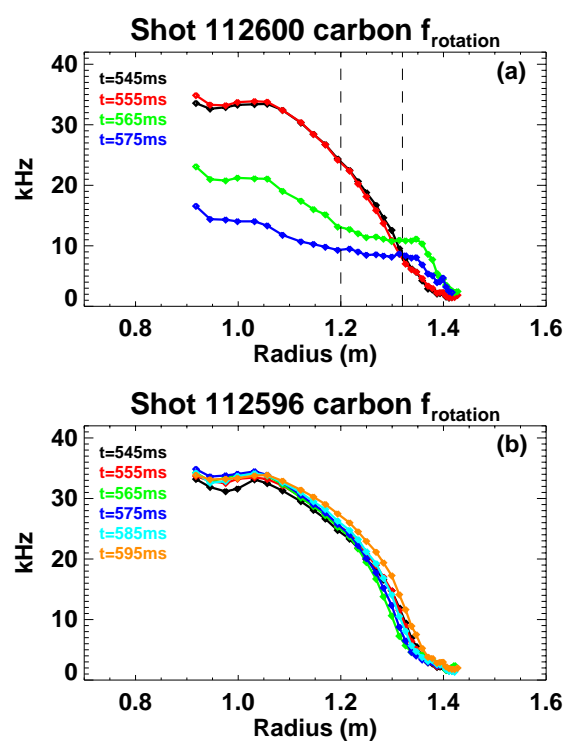

Figure 4: Rotation profile evolution for discharges from Figure 1. tions. This model predicts a peak radial field of 50-100 Gauss in the core with most of the core experiencing a perturbation of at least 20 Gauss, while radial field perturbations of 10-50 Gauss are estimated outside the core and approaching the edge. The coupled modes will initially rotate differentially with respect to the sheared plasma rotation, so rotation damping is expected in the plasma core while acceleration should occur at larger 
$r / a$. Estimates of the rotation profile damping rates have been computed using these perturbed magnetic fields converted to a simple cylindrical representation of the mode perturbed field [11] using the flux-surface-average $B_{\perp}$ from the $3 \mathrm{D}$ island model.

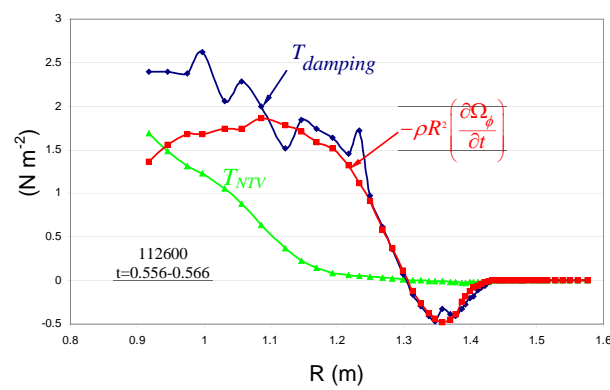

Figure 5: Measured rotation damping profile during early $1 / 1$ growth vs. predicted damping. Contribution from $N T V$ is also shown.
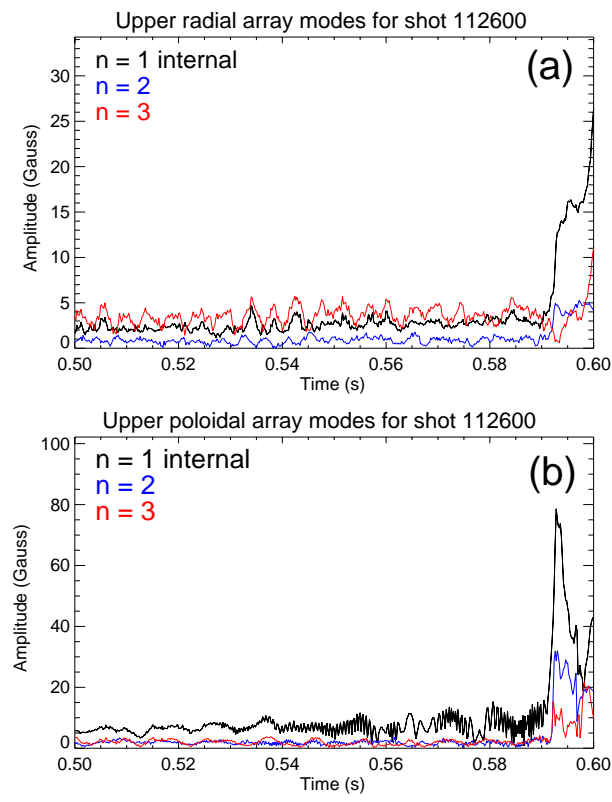

Figure 6: n=1-3 magnetic field perturbations from (a) upper radial and (b) upper poloidal in-vessel $R W M$ sensors for shot 112600.
As seen in Figure 5, there is reasonable agreement between the measured rotation damping $=-\rho R^{2} \frac{\partial \Omega_{\phi}}{\partial t}$ and the predicted total damping $=T_{\text {damping }}$ including the effects of axisymmetric fluid viscosity, entrainment of plasma mass in the large $2 / 1$ island, and NTV arising from mode-induced non-axisymmetry. The coupled-mode frequency very nearly matches the plasma rotation frequency at the $2 / 1$ surface, so the largest initial differential rotation between mode and plasma occurs in the plasma core. For this reason, the rotation damping contribution from NTV $\left(T_{N T V}\right.$ in Figure 5) is only strong in the plasma core $(R<$ $1.2 \mathrm{~m})$ where the perturbed fields from the $1 / 1$ mode are large. We infer from this modeling that the net effect of the 1/1 mode NTV torque is to signficantly widen the region of flattened rotation relative to what would be induced by the $2 / 1$ mode alone.

While the damping model above appears consistent with the observed rotation flattening, the explanation for the decay of the flattened rotation profile is less clear. To better diagnose the low-frequency MHD activity potentially responsible for the rotation decay, an array of 48 new in-vessel magnetic field sensors has been installed in NSTX for the detection of error fields, locked modes, and resistive wall modes. These sensors measure radial field perturbations normal to the primary passive plates and poloidal field perturbations at the ends of the plates both above and below the midplane. There are 12 sensors in each toroidal array allowing toroidal mode number determination ranging from $n=1$ to 3 . Figure 6 a shows the radial field perturbation amplitudes as determined by these sensor arrays during the rotation decay phase preceding the final $\beta$ collapse. As is evident from the figure, there is no obvious change in the radial field signals from the time of $1 / 1$ mode onset at $560 \mathrm{~ms}$ until the final collapse $30 \mathrm{~ms}$ later. Figure $6 \mathrm{~b}$ shows similar behavior except the rotating modes appear (aliased by the $5 \mathrm{kHz}$ digitizer sampling) starting around $530 \mathrm{~ms}$ until the collapse phase. In both figures, there is no clear evidence of a slowly growing nearly stationary mode such as a resistive wall mode (RWM) which might be responsible for the rotation decay.

If a quasi-stationary mode is not causing the decay, other island effects may be responsible. First, the diffusion and/or loss of fast ions in the presence of a large island structure could reduce the torque applied to the plasma by NBI. Second, Figure 1 indicates that 
the edge poloidal field perturbation amplitude nearly doubles when the coupled islands are present. Assuming a similar scaling for the island $B_{r}$, this could quadruple the wall torque applied to the mode. Further, as the mode slows, the wall torque would increase since initially $\omega \tau_{\text {wall }} \gg 1[10]$. Once the mode rotation frequency falls below $2 \mathrm{kHz}$, it rapidly decreases in frequency, quickly locks to the wall, and then penetrates the passive plates and vacuum vessel. Another possible explanation is that once the rotation falls below this critical value, an RWM is destabilized $[12,13]$ and rapidly grows on a $1 \mathrm{~ms}$ time-scale. Whatever the precise identity of the mode that causes the final disruption, this locked state ultimately induced a vertical displacement event (VDE) which caused a plasma current disruption in shot 112600.

\section{Mode saturation physics}

As shown above, a large 1/1 mode can contribute to significant degradation of energy and momentum confinement sometimes to the point of island locking and/or RWM destabilization leading to complete collapse of the plasma. In situations when the $1 / 1$ mode amplitude is not as large and the mode is not strongly coupled to other modes, it can exist in more benign saturated states as discussed in more detail below.

\subsection{Fast ion stabilization}

Thermal and energetic trapped ions are well known [14] to help stabilize the internal kink mode. In tokamaks, this stabilization can delay the occurrence of normal sawteeth, allow the current profile to penetrate on axis, and ultimately lead to monster sawteeth $[15,16]$ with large inversion radius. As stated previously, cyclic sawtooth activity is relatively rare in high- $\beta$ discharges in NSTX, and many of the highest- $\beta$ discharges are instead confinement limited by saturated $m / n=1 / 1$ modes. This confinement degradation is evident in Figure 1 which shows both roll-over in $\beta$ and a large fractional drop (30\%) in (beam-target) neutron rate at mode onset. For other discharges with $1 / 1$ instabilities and similar drop in neutron rate, Neutral Particle Analyzer (NPA) data indicates a depletion of the fast ion population by a factor or 3 or more for energies above $20-30 \mathrm{keV}$. This is most consistent with fast ion loss since diffusion would likely move the fast ions outward to a region of higher neutral density yielding increased NPA signal. Thus, the 1/1 mode appears to expel many of the ions which presumably aid in linearly stabilizing it. Thus, it appears unlikely that fast ions contribute strongly to non-linear saturation unless the ideal instability drive is also significantly reduced by depletion of the core fast ions.

\subsection{Strong rotational shear}

Centrifugal and flow-shear effects have been studied previously in the context of internal kink stability $[17,18,19]$. For a high aspect ratio tokamak with circular flux surfaces, the internal kink instability growth rate including sheared rotation can be expressed as [17]:

$$
\begin{aligned}
\gamma_{0} & =-\frac{\pi r_{s} \omega_{A}}{\sqrt{3}\left|q^{\prime}\right| R_{0}^{2}} \hat{W}_{i}, \Delta \beta_{P}^{2} \equiv\left(\beta_{p}^{2}-\frac{13}{144}\right) \\
\hat{W}_{i} & \approx-3 r_{s}\left|q^{\prime}\right| \Delta \beta_{P}^{2}+\left(\frac{2}{\epsilon_{V}^{2}}-\frac{1}{\epsilon_{\rho}^{2}}\right) \frac{V_{0}^{2}}{V_{A}^{2}}
\end{aligned}
$$

Here $\epsilon_{V}=L_{V} / R_{0}$ and $\epsilon_{\rho}=L_{\rho} / R_{0}$ where $L_{V}$ and $L_{\rho}$ are the velocity and density profile scale lengths normalizing the minor radius for parabolic profiles. Thus, high flow speed 
relative to the Alfvén speed (high $\frac{V_{0}}{V_{A}}$ ) and strong flow shear (small $\epsilon_{V}$ ) are potentially strongly stabilizing for the internal kink mode. The potential stabilizing effect of sheared toroidal flow on the 1/1 mode in NSTX has previously been studied non-linearly with the M3D code [20]. For typical parameters in NSTX (central $\frac{V_{0}}{V_{A}}$ up to 0.4), M3D studies find that nonlinear saturation of the $1 / 1$ mode is not possible via sheared-flow alone for fixed momentum source rate. Rather, the growth rate is reduced by a factor or 2 to 3 , but complete reconnection still occurs in the simulations. As a result of the reconnection, the core pressure and rotation profiles are quickly flattened. Thus, any flow shear that could stabilize the mode non-linearly is reduced by the mode itself. However, the simulations also show that if the rotation shear is forced to be maintained during the mode growth, saturation does indeed occur. In the experiment, most discharges with core 1/1 activity exhibit core rotation flattening similar to that shown in Figure 4. Thus, sheared toroidal flow also appears to be an unlikely explanation for mode non-linear saturation.

\subsection{Viscous effects}

In the linear theory of resistive internal kink mode stability, it has been shown [21] that viscous dissipation is potentially stabilizing for the mode. The resistive treatment is at least partially applicable for NSTX since $\nu_{e i} \tau_{A} \approx 0.3$ using an electron-ion collision rate derived from the neoclassical parallel resistivity. The stabilization strength of viscous dissipation can be readily estimated for high aspect ratio tokamak plasmas with circular cross section when the MHD growth rate is less than the ion diamagnetic frequency. In this regime, perpendicular viscosity is stabilizing when $\hat{D} \geq D_{\text {crit }}$ where $\hat{D} \equiv \nu_{\mu} / \nu_{\eta}, \nu_{\mu}$ and $\nu_{\eta}$ are viscous and resistive relaxation rates respectively and $\hat{D}_{c r i t}=5\left(\omega_{A}^{2} /\left|\omega_{d i} \hat{\omega}_{* e}\right|\right) \lambda_{H}^{2}$. We note that $\hat{D} \approx 0.3\left(m_{i} T_{e} / m_{e} T_{i}\right)^{0.5} \beta_{e}$ implying that perpendicular viscous effects are significantly enhanced by high $\beta$. Applying the stability criteria to low aspect ratio and shaped plasmas (i.e. beyond its regime of strict applicability), near the time of $1 / 1$ mode onset for discharge 112600 in Figure $1, \omega_{A} \approx 10^{6}, \omega_{* i} \approx 2 \times 10^{4}, \hat{\omega}_{* e} \approx-3 \times 10^{4}$, and $\lambda_{H} \approx 0.02$. For these parameters, $\gamma_{M H D} \approx 2.3 \times 10^{4} \approx \omega_{* i}, \hat{D} \approx 2$, and $\hat{D}_{\text {crit }} \approx 4$. Consistent with the experiment, for these parameters the mode is estimated to be linearly unstable since $\gamma_{M H D}>\omega_{* i} / 2$ and viscous effects are roughly a factor of 2 too low to provide linear stability. We therefore conclude that unless the perpendicular viscosity is somehow driven anomalously high through nonlinear effects associated with mode growth, it is unlikely that viscous effects play a role in mode saturation. The NTV rotation damping process discussed above and the kinetic profile data shown in Figure 7 below highlight the potentially strong changes in plasma transport and flows induced by magnetic islands. To contribute to saturation, such effects would likely have to be strong and active over the relevant length scales of the reconnection region of the $1 / 1$ mode which could be as large as $\rho_{s i} \approx 1-2 \mathrm{~cm}$ in width and $\Delta \theta \approx 120^{\circ}$ in poloidal extent.

\subsection{Island pressure peaking and non-linear 2-fluid effects}

Nonlinear simulations of the $1 / 1$ mode using the M3D code in the MHD approximation [20] did find saturated states under some conditions. Such states were not reproducibly obtained in the simulations however, as these states resulted after several crash cycles and are apparently the result of the pressure becoming locally highest inside the island [22]. In some discharges, the saturated $1 / 1$ mode is sufficiently longlived that several Thomson scattering profiles can be obtained capturing the mode island structure. Figure 7 shows the time evolution of such profiles for 1MA shot 108103 
which becomes $1 / 1$ unstable at $\mathrm{t}=228 \mathrm{~ms}$ and reaches $\beta_{T}=30 \%$ near $\mathrm{t}=300 \mathrm{~ms}$ [2]. Figure $7 \mathrm{a}$ at $\mathrm{t}=227 \mathrm{~ms}$ prior to mode onset shows the electron temperature peaking near the magnetic axis $R_{\text {axis }}=1.0 \mathrm{~m}$ as reconstructed by EFIT. During the saturation phase at $\mathrm{t}=243 \mathrm{~ms}$, the Thomson scattering system is apparently imaging the mode phase where the hot core has been displaced outwards. At $\mathrm{t}=260 \mathrm{~ms}$, the opposite phase is evident with the hot core located on the inboard side with a $T_{e}$ flat-spot on the low-field side. By $\mathrm{t}=277 \mathrm{~ms}$ as the island width is shrinking in the SXR inversions, the central $T_{e}$ has largely recovered, and narrow temperature flat-spots are apparent on both sides of the magnetic axis. Figure $7 \mathrm{~b}$ shows that the electron pressure evolution is very similar to the temperature evolution, as the density profile is relatively flat and changes little with island phase when the mode is present. Figure 7c shows that the $20 \mathrm{~ms}$ time-average ion temperature is initially peaked, flattens and broadens during the early growth phase as does the rotation, and eventually recovers both on-axis and off-axis while remaining depressed near the island region during the mode saturation. With respect to pressure peaking inside the island, the electron data suggests that the displaced core remains hotter (and with higher pressure) than the island region, and the ion data is consistent with lower ion temperature in the island also. Thus, it appears unlikely that pressure peaking inside the island is responsible for mode saturation.

One noteworthy feature of the data in Figure $7 \mathrm{~b}$ is the obvious displacement of the core at $t=243 \mathrm{~ms}$. The pressure data points outside $\mathrm{R}=1.3 \mathrm{~m}$ are nearly identical at $\mathrm{t}=227 \mathrm{~ms}$ and $\mathrm{t}=243 \mathrm{~ms}$, indicating that the displacement outside the core is small - consistent with the USXR data (not shown). Further, the local electron pressure gradient is clearly significantly higher in the inferred island $\mathrm{X}$-point region near $\mathrm{R}=1.25-1.3 \mathrm{~m}$ at $\mathrm{t}=243 \mathrm{~ms}$. If this pressure gradient enhancement also occurs in the ion channel, quasilinear enhancement of $\omega_{* i}$ could also play a role in non-linear saturation of the mode [23]. In the twofluid theory of the $m=1$ mode [24] in the limit of $\omega_{* e}=0$, the displacement of the core enhances both the pressure gradient and magnetic shear, and results in a criterion for quasilinear stability: $\alpha \omega_{* i} \tau_{A}>$
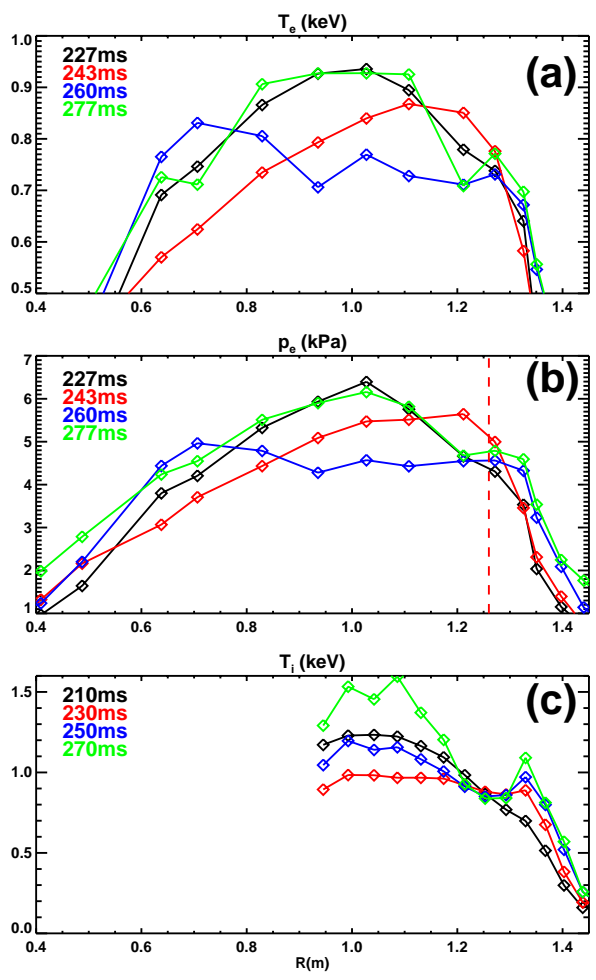

Figure 7: (a) $T_{e}$, (b) $p_{e}$, and (c) $T_{i}$ in shot 108103.
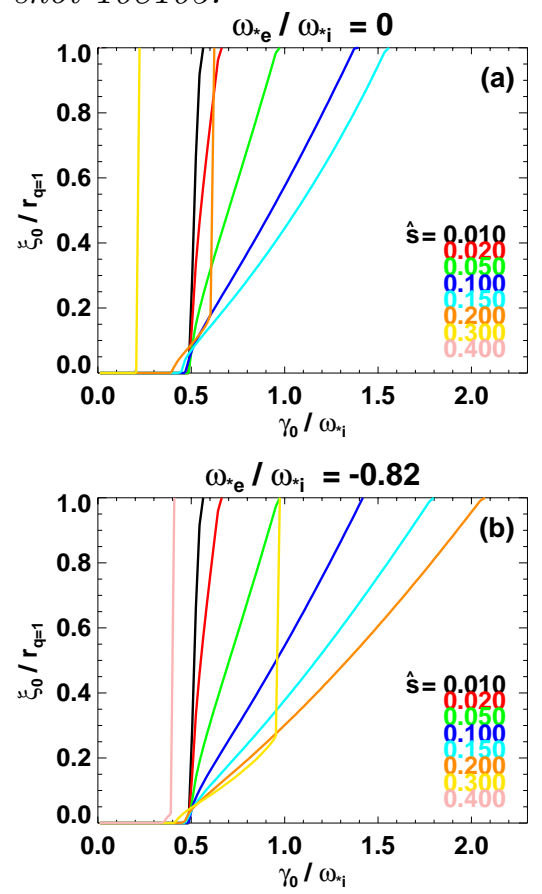

Figure 8: Displacement of plasma core for nonlinear $\omega_{* i}$ stabilization. $2 q^{\prime} \sqrt{\lambda_{h}^{2} / \bar{q}^{\prime 2}+\bar{q}^{\prime 2}\left(\rho_{s}^{2}+5 d_{e}^{2}\right) / 2}$. Here $\lambda_{h}$ is the ideal mode layer width, $\rho_{s}$ is the ion sound- 
speed Larmor radius, and $d_{e}$ is the collisionless electron skin depth. The pressure gradient enhancement factor $\alpha=1+2 \chi^{2}$, the shear enhancement factor $\bar{q}^{\prime}=1+6 \chi^{2}$, and $\chi=\xi_{0} / 2 \pi \lambda_{h}$ where $\xi_{0}$ is the radial displacement of the magnetic axis in the presence of the island. Using the relation $\gamma_{0} \tau_{A}=q^{\prime} \lambda_{h}=\sqrt{3} \pi \epsilon_{q=1}^{2} \Delta \beta_{P}^{2}$, Figure 8 plots the normalized displacement of the core predicted by the criterion above versus the normalized ideal instability growth rate and normalized magnetic shear $\hat{s}=r d q / d r$ at the $q=1$ surface for shot 108103 at $\mathrm{t}=220 \mathrm{~ms}$. With zero electron diamagnetic drift, Figure 8a shows that for NSTX parameters, there is a limited range of magnetic shear $(\hat{s}=0.1-0.15)$ where saturated normalized displacements similar to the experimental values of $0.3-0.6$ are accessible with ideal linear growth rates well above the nominal threshold of $\gamma_{0} / \omega_{* i}=0.5$. Figure $8 \mathrm{~b}$ shows that saturation should occur over a wider range of instability drive and shear (especially near $\hat{s} \approx 0.2$ ) when electron diamagnetic effects are included in the quasilinear dispersion relation. The potential of this theory to explain $1 / 1$ mode saturation in NSTX will be tested in the near-term utilizing MSE-constrained equilibrium reconstructions.

\section{Summary}

Internal kink instabilities have been observed to flatten rotation in the plasma core, degrade thermal and fast particle confinement, and in some cases contribute to the complete loss of plasma angular momentum and stored energy in many of the highest toroidal $\beta$ discharges of NSTX. In many cases, the modes do not apparently undergo complete reconnection, and can sometimes persist in a saturated state for 10-100 initial growth times. Several possible saturation mechanisms have been investigated, but none appear to individually dominate the saturation process. Future studies with the M3D code combining rotation, fast-particle, and two-fluid effects may provide more insight into the saturation physics of the internal kink mode in NSTX.

This work supported by the US-DoE contract DE-AC02-76CH03073 (PPPL) and grants DE-FG02-99ER54524 (CU) and DE-FG02-99ER54523 (JHU).

\section{References}

[1] ONO, M., et al., Nucl. Fus. 40 (2000) 557.

[2] MENARD, J. E., et al., Nucl. Fus. 43 (2003) 330.

3 GATES, D., et al., Phys. Plasmas 10 (2003) 1659.

4 LAO, L. L., et al., Nucl. Fus. 25 (1985) 1611.

5] SABBAGH, S. A., et al., Nucl. Fus. 41 (2001) 1601.

6] SABBAGH, S. A., et al., Phys. Plasmas 9 (2002) 2085.

7] LEVINTON, F., to be published.

8. STUTMAN, D., et al., Rev. Sci. Instrum. 70 (1999) 572.

9 GREENFIELD, C. M., et al., Phys. Plasmas 11 (2004) 2616.

[10] FITZPATRICK, R., Nucl. Fus. 33 (1993) 1049.

11] LAZZARO, E., et al., Phys. Plasmas 9 (2002) 3906.

12. SABBAGH, S. A., et al., Nucl. Fus. 44 (2004) 560.

13] SABBAGH, S. A., this conference, Paper EX/3-2.

14] COPPI, B., et al., Phys. Fluids B 2 (1990) 927.

15] CAMPBELL, D. J., et al., Phys. Rev. Lett. 60 (1988) 2148.

[16] BERNABEI, S., et al., Phys. Rev. Lett. 84 (2000) 1212.

17. WAELBROECK, F. L., Phys. Plasmas 3 (1996) 1047.

18 WAHLBERG, C. and BONDESON, A., Phys. Plasmas 7 (2000) 923.

19] GRAVES, J. P., et al., Phys. Plasmas 10 (2003) 1034.

20] PARK, W., et al., Nucl. Fus. 43 (2003) 483.

21] PORCELLI, F. and MIGLIUOLO, S., Phys. Fluids 29 (1986) 1741.

22] PARK, W., MONTICELlO, D. A., and CHU, T. K., Phys. Fluids 30 (1987) 285.

23] ROGERS, B. and ZAKHAROV, L., Phys. Plasmas 2 (1995) 3420.

[24] ZAKHAROV, L. and ROGERS, B., Phys. Fluids B 4 (1992) 3285. 


\section{External Distribution}

Plasma Research Laboratory, Australian National University, Australia

Professor I.R. Jones, Flinders University, Australia

Professor João Canalle, Instituto de Fisica DEQ/IF - UERJ, Brazil

Mr. Gerson O. Ludwig, Instituto Nacional de Pesquisas, Brazil

Dr. P.H. Sakanaka, Instituto Fisica, Brazil

The Librarian, Culham Laboratory, England

Mrs. S.A. Hutchinson, JET Library, England

Professor M.N. Bussac, Ecole Polytechnique, France

Librarian, Max-Planck-Institut für Plasmaphysik, Germany

Jolan Moldvai, Reports Library, Hungarian Academy of Sciences, Central Research Institute for Physics, Hungary

Dr. P. Kaw, Institute for Plasma Research, India

Ms. P.J. Pathak, Librarian, Institute for Plasma Research, India

Ms. Clelia De Palo, Associazione EURATOM-ENEA, Italy

Dr. G. Grosso, Instituto di Fisica del Plasma, Italy

Librarian, Naka Fusion Research Establishment, JAERI, Japan

Library, Laboratory for Complex Energy Processes, Institute for Advanced Study, Kyoto University, Japan

Research Information Center, National Institute for Fusion Science, Japan

Dr. O. Mitarai, Kyushu Tokai University, Japan

Dr. Jiangang Li, Institute of Plasma Physics, Chinese Academy of Sciences, People's Republic of China

Professor Yuping Huo, School of Physical Science and Technology, People's Republic of China

Library, Academia Sinica, Institute of Plasma Physics, People's Republic of China

Librarian, Institute of Physics, Chinese Academy of Sciences, People's Republic of China

Dr. S. Mirnov, TRINITI, Troitsk, Russian Federation, Russia

Dr. V.S. Strelkov, Kurchatov Institute, Russian Federation, Russia

Professor Peter Lukac, Katedra Fyziky Plazmy MFF UK, Mlynska dolina F-2, Komenskeho Univerzita, SK-842 15 Bratislava, Slovakia

Dr. G.S. Lee, Korea Basic Science Institute, South Korea

Institute for Plasma Research, University of Maryland, USA

Librarian, Fusion Energy Division, Oak Ridge National Laboratory, USA

Librarian, Institute of Fusion Studies, University of Texas, USA

Librarian, Magnetic Fusion Program, Lawrence Livermore National Laboratory, USA

Library, General Atomics, USA

Plasma Physics Group, Fusion Energy Research Program, University of California at San Diego, USA

Plasma Physics Library, Columbia University, USA

Alkesh Punjabi, Center for Fusion Research and Training, Hampton University, USA

Dr. W.M. Stacey, Fusion Research Center, Georgia Institute of Technology, USA

Dr. John Willis, U.S. Department of Energy, Office of Fusion Energy Sciences, USA

Mr. Paul H. Wright, Indianapolis, Indiana, USA 
The Princeton Plasma Physics Laboratory is operated by Princeton University under contract with the U.S. Department of Energy.

\author{
Information Services \\ Princeton Plasma Physics Laboratory \\ P.O. Box 451 \\ Princeton, NJ 08543
}

Phone: 609-243-2750

Fax: 609-243-2751

e-mail: pppl_info@pppl.gov

Internet Address: http://www.pppl.gov 